\title{
Physical/Cyber Objects Management Framework for Multiple-Area Detectable RFID
}

\author{
Masayuki Iwai, Ryo Osawa, Suzuki Kei, Takuya Imaeda, and Hideyuki Tokuda \\ Graduate School of Media and Governance, Keio University \\ 5322 Endo, Fujisawa, Kanagawa, 252-8520, Japan \\ \{tailor,ryo, suzuk, che, hxt\}@ht.sfc.keio.ac.jp \\ http://www.ht.sfc.keio.ac.jp/smart-furoshiki
}

\begin{abstract}
Recently, there is lots research for tangible objects which enables to support users everyday's life. However, due to the high price of sensors, endusers hesitate to attach such devices to physical objects. Even worth, batteries of embedded devices should despoil the living environment. Therefore, the lowprice system to detect users' phisical objects without battery is needed. We will propose a novel hardware platform using cheap RFID tags which can attach on any everyday physical objects. We have designed and implemented two size of RFID systems which have flexible multiple area antennas to support manage users' physical objects. This paper describes details of Smart-Furoshiki system and its applications.
\end{abstract}

Keywords: RFID, Multiple-area Detection, Physical Objects Management.

\section{Introduction}

Nowadays, number of researchers which have proposed ubiquitous systems to detects physical objects in users' everyday life are increasing. These systems use lots of embedded computers and sensors to detects human activities [6][10]. As in our past projects, we have been creating non-export DIY ubiquitous system, for example smart furniture [3 12 12 4 without thinking the cost of back-end system.

However, it is difficult to setup all of devices for users who are unfamiliar with computing technology. To make matters worse, buying many of sensors is too expensive to end users. Most of research has ignored such economical cost and users' maintainability. To give an actual example, documents using at a weekly meeting should be not worth to attach sensor-embedded devices which costs more than $15 \$$. Even worth, batteries of sensor-embedded devices should despoil the earth environment. Therefore, the low-priced system to support users' daily life without battery is needed. We will propose a novel hardware platform using low cost RFID tags which can attach on any everyday items. We have design and implemented two size of RFID system which has flexible multiple area antennas to support accumulation of users' context.

Our reaseach goal is to develop software and harware which enable non-expert users to create smart objects without battery in cheaper way . We use RFID tags, which is less than 10 cents and they are easy to attach to any kinds of phisical objects.

R. Obermaisser et al. (Eds.): SEUS 2007, LNCS 4761, pp. 11-19, 2007.

(C) IFIP International Federation for Information Processing 2007 


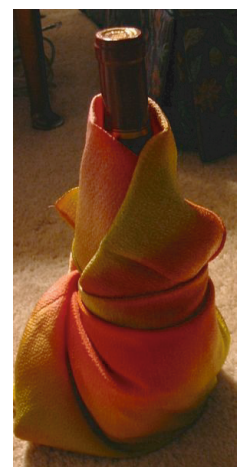

Fig. 1. Furoshiki: traditional Japanese wrapping cloth

We propose a novel hardware called Smart-Furoshiki which is a sensorized cloth for supporting office and home activities. "Furoshiki" is a type of traditional Japanese wrapping cloth that can were frequently used to transport clothes, gifts, or other goods(see Figure 1). As Furoshiki is so flexible and simple, it can use lots of porpose. For example it can wrap any type of shapes from bottles to box. It also can cover on the important things, or spread under cloth.

Smart-Furoshiki has more than 4 passive RFID antennas and a tiny RFID reader. Beause of it's flexbility, Smart-Furoshiki can be used universally for the porpose of tablecloth, tapestry and cover. Users can easily use Smart-Furoshiki without configuring computers, sensors and networks inside each Smart-Furoshiki. This paper describes details of Smart-Furoshiki and its software framework of phisical objects managemenet system.

\section{Hardware Architecture}

In this section, we describe the harware system architecture of Smart-Furoshiki.For the popose of adapting lots of usage, we have develop two type of Smart-Furoshiki, large size and mobile size.

\subsection{Desktop-Size Furoshiki}

Desktop-size version can use in a office and home environment. This type can detect not only RF-IDs of objects but also the existence area ID. By using these two type of ID, the system can detects the context information. An example scenario is that a userfs car key and her/his wallet are always put nearside on the Smart-Furoshiki.

Hardware of Desk-Top Size Furoshiki. Figure 2 and 3 leftside show the architecture of Smart-Furoshiki. Smart-Furoshiki has 8 RFID antennas and 8 tags. RFID reader uses 8 antennas on timesharing system due to avoid the radio wave collisions between antennas. The reader is special model Takaya TR3-D002C-8 which has 8 antenna channels. Each antenna is made by conductive fabric [11] for the purpose of bending it flexibly 


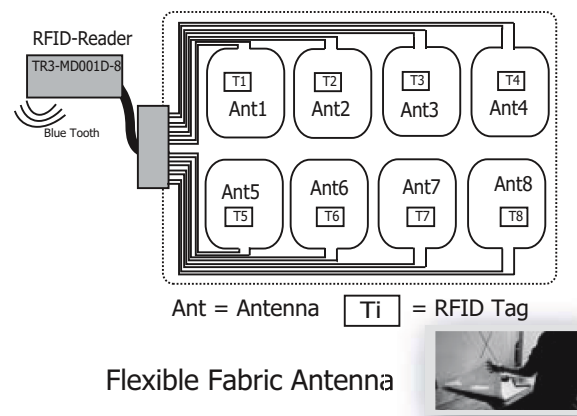

Fig. 2. Architecture of the Smart-Furoshiki and Flexible Fabric Antenna

as shown in Figure2. The material of fabric antenna has special film of metal. It has a thickness of $0.125 \mathrm{~mm}$. The density is $72 \mathrm{~g}$ per $\mathrm{m}^{2}$. According to the tag size, the reading distance is from $-18 \mathrm{~cm}$ to $18 \mathrm{~cm}$.

The $13.56 \mathrm{MHz}$ tags are stitched into the Furoshiki at the center of each antenna. Every antenna is unified as the cable to the 8 port RFID reader. The Smart-Furoshiki is separated in to 8 areas, which is cover Furoshikie range of RFID antenna. To simplify the explanation, we user $A n t_{1}-A n t_{8}$ as the name of antennas and $T_{1}-T_{8}$ as RFID tags. $T_{i}$ is placed at the center of $A n t_{1}$ and always detected by $A n t_{i}$.

Figure 3 right side shows the middleware screen shot of Smart-Furoshiki. SmartFurosiki can read multiple objects ID in multiple areas unlike other RFID system. The middleware has also has application repository and multicast data transition architecture to support applications developers.

\subsection{Mobile-Size Furoshiki}

Users carry many kinds of everyday objects including books, papers, cell phone, magazines, DVDs, wallet, and music player. Furthermore, they have needs both to reduce things left behind the bag and not to lose something important work related on the something on the bags. To satisfy these needs, we have developed mobile type of Smart-
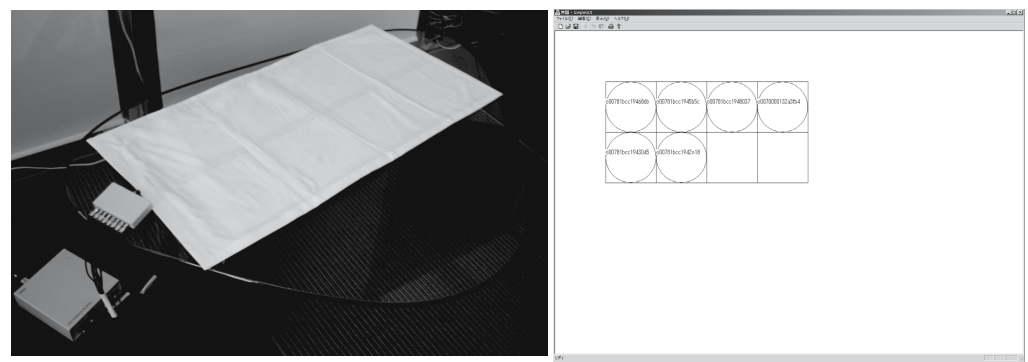

Fig. 3. Exterior of Smart-Furoshiki 


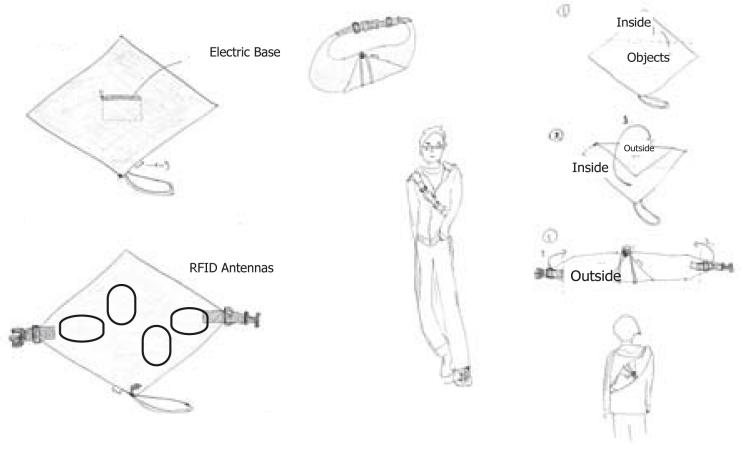

Fig. 4. Use Case of Mobile Size Furoshiki

Furoshiki. All the electric devices, such as bluetooth communication module, RFID reader, and antenna much condenser circuits, and battery, are accumulate into a small electric box(see Figure 5).

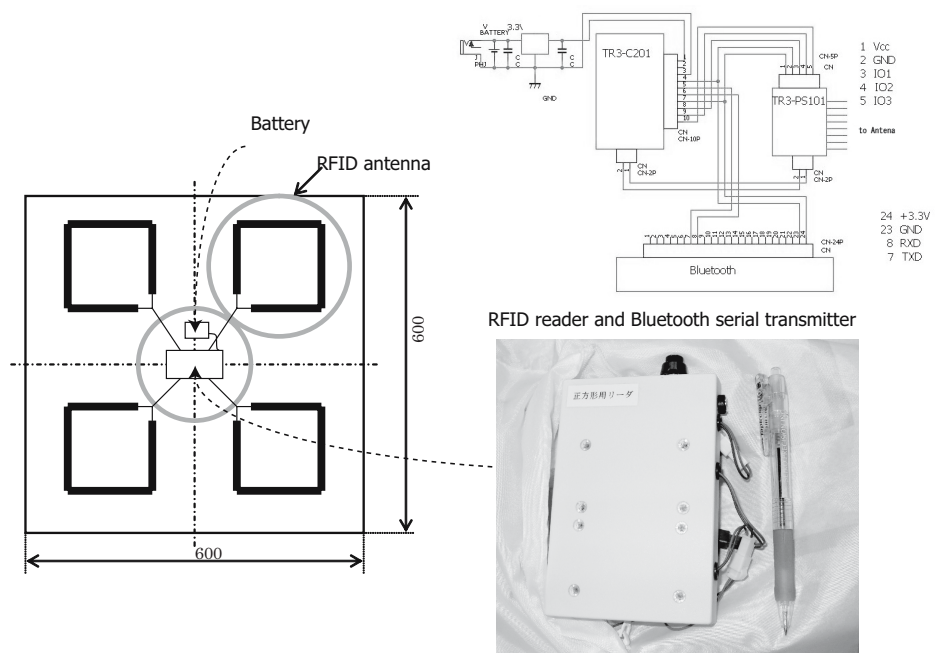

Fig. 5. Harware of Mobile size Smart-Furoshiki

Hardware. Figure 4 show the use case of Mobile-Size Furoshiki. This type of Furoshiki can put everyday objects inside and can carry it anyplace. The system can recognize the users' belongings, a thing left behind and the duration time to bring. System can gather these users context even if users are outside of office.

\section{Software Framework of Smart-Furoshiki}

In this section, we describe the software framework to manage phicical objects in Smart-Furoshiki system. 


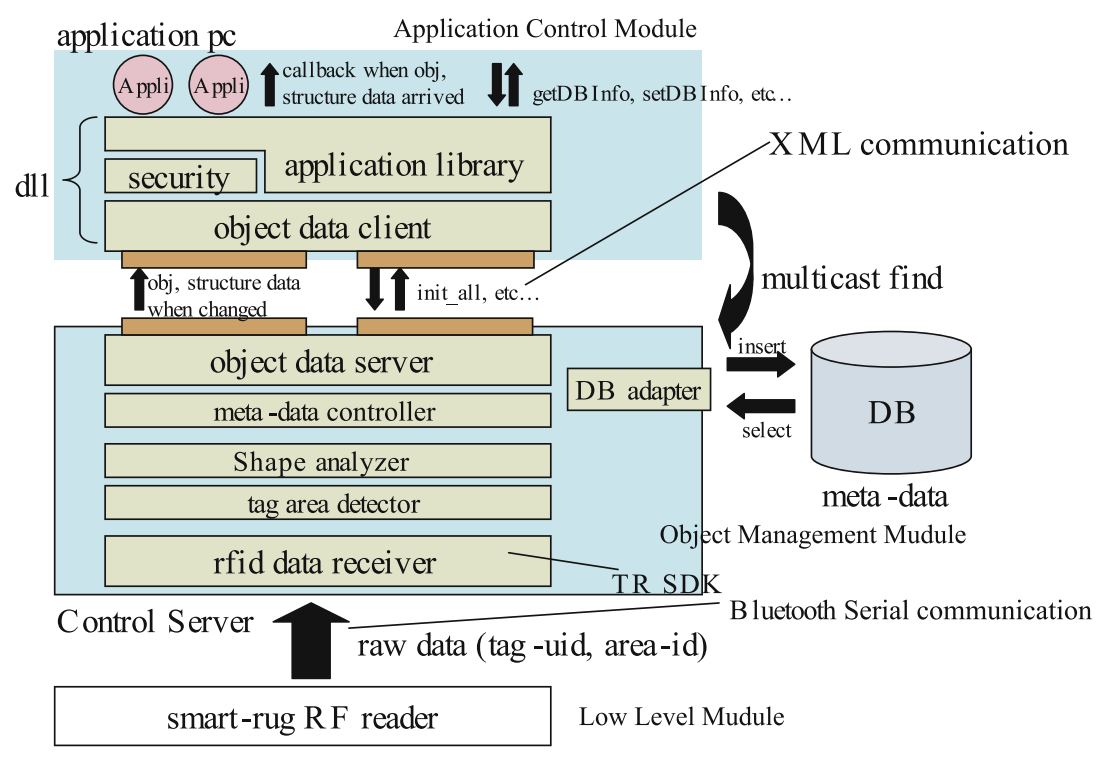

Fig. 6. Middleware Framework of Smart-Furoshiki

\subsection{Total Framework of Smart-Furoshiki Middleware}

Smart-Furoshiki Middleware are separated into 3 modules as shown in Figure 6 SmartFuroshiki Middleware are separated into 3 modules as shown in Figure 6. First one is most low level software which only detects RFID numbers eventually.This module send data to Object Management Layer eventually using bluetooth communication Second module is Object Management Layer which analyze structure of Smart-Furosihki. Analyzing structure is mentioned in next subsection. This Object Management Layer has a meta-data DB which is mapping between tag-ID and physical objects. This meta-data DB also obtain the applications' meta information to launch. Object Management Layer send detected/detached RFID tag information to upper layer using multicast network communication.

Third module, most upper layer, is on the client side as shown in Figure6. This Application Control Modules try to control suitable application for users using information from Object Management Layer. Application Control Modules, which are implemented in windows DLL, are always communicate to the Object Management Layer. This layer also controls the relations of tags which must detect in the same time to support secure applications.

\subsection{Algolism of Shape Recognition}

Smart furoshiki is so flexible that it can be folded into any shape. To recognize the shape of Smart-Furoshiki, we are using below algorisms.

When $A n t_{1}$ detects $T_{4}$, the shape of Smart-Furoshiki is folded in to half as figure 7 When $A n t_{2}$ detects $T_{1}$ and $A n t_{3}$ detects $T_{4}$ simultaneously, the shape of Smart- 

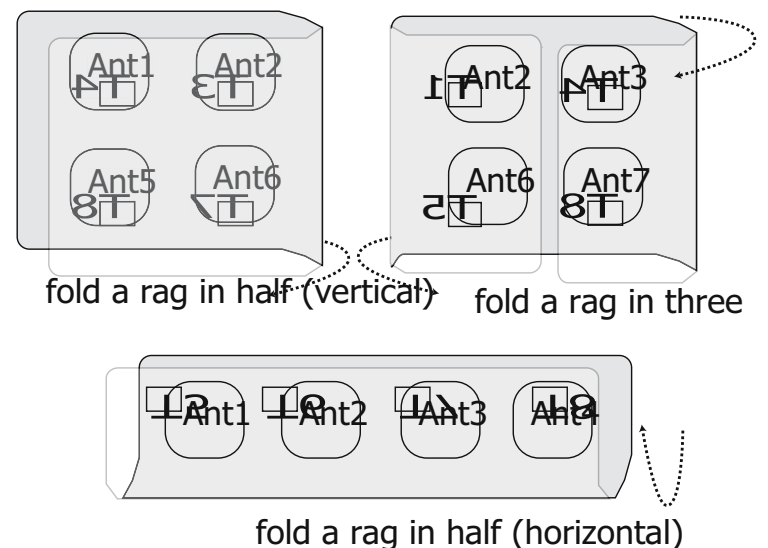

Fig. 7. Mechanism of Self Shape Recognition

Furoshiki is folded in to three. In the same way, the detection $T_{2}$ from $A n t_{1}$ means that the shape is folding into half horizontally. In the case that there are more than 2 Smart-Furoshikis, We can estimate physical overlapping of Furoshikis by reading the neighbor's tags. Thus, the Smart-Furoshiki can detects tags' ID, detected area on it, and physical shape of Furoshiki.

\section{Applications}

To assume the usage in office environment of Smart-Furoshiki middleware, We have 3 applications based on the affordance of Smart-Furoshiki, laying, covering, and hanging.

\subsection{Supporting Collaborative Works by Laying Smart-Furoshiki on A Desk}

Currently, the number of documents and data which are treated in cyber space is increasing. However, cyber desktop management systems can not recognize objects on a physical desktop area, correctly. (ex. Books, DVD jackets, pens, papers, lights, electrical appliances ,room sensors) On the other hand, physical objects can not recognize either cyber object which used by same person. This Smart-Furoshiki is a novel hardware and desktop management system which can handle both cyber and physical objects.

The users can lay Smart-Furoshiki on a desk. The Smart-Furoshiki supports cooperation between objects on it. Objects on Smart-Furoshiki are identified by RF-ID. Figure 8 shows it. When computers are brought close, those computers share directories each other. When the users edit the same file on those computers, the changes are immediately updated on the editors each other (1). Also Smart-Furoshiki supports cooperation between computers and objects. For example, the users place a music CD near a computer, and the music data in CD is copied to the computer (2). Besides, Smart-Furoshiki supports cooperation between objects. The users can see the movies on the display putting the movie DVD near the display (3). 

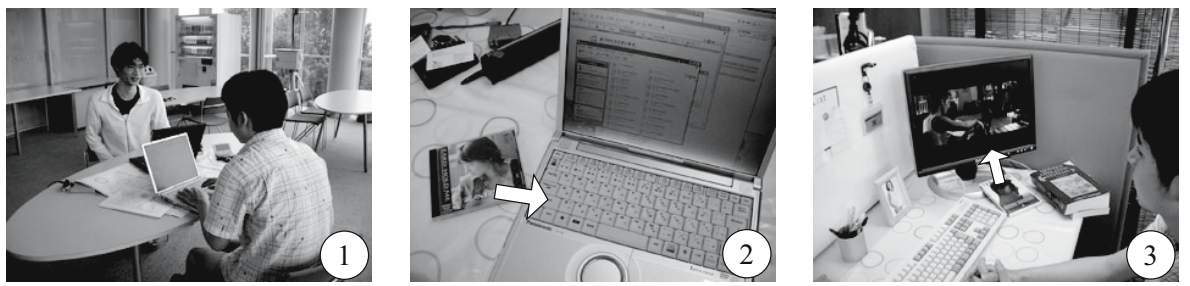

Fig. 8. Supporting Collaborative Works by Laying Smart-Furoshiki on A Desk

\subsection{Managing Objects Covered with Smart-Furoshiki}

Users can manage the users' objects covered with Smart-Furoshiki. The scenario is showed in Figure 9. First, the user attaches an RF-ID tag to the user's objects and registers it to Smart-Furoshiki (1). When the user puts the user's object that is registered before, the user is authenticated and login the PC on the desk. The authenticated user can work at the desk(2). When the user leaves the desk, by covering the objects with Smart-Furoshiki the user visually hide them and log off the PC (3). When the user wants to uncover the objects hidden by Smart-Furoshiki, the user must put the user's object. If a user that is not authenticated put off Smart-Furoshiki, the Furoshiki informs the home security system of the theft. Also, Smart-Furoshiki reminds a user of the object left behind on it. For example, when a user always brings the user's cell phone, watch and wallet together Smart-Furoshiki remembers this practice. When the user left the watch behind although the user brought cell phone and wallet Smart-Furoshiki warns the user.

\subsection{Wall Type Task Schedular Using Smart-Furoshiki}

The third example is the application to manage users' tasks. The scenario is shown in Figure 5. Smart-Furoshiki hangs on a wall. The wall is separated into some areas. The area means the priority of tasks, such as "Emergency task" and "Pending task". First, a user writes a memo pad about the user's task with an electronic pen that is able to convert handwriting to digital data [7], and pins that memo pad to Smart-Furoshiki (1). The application registers a task content written on this memo pad as pinned areas' @ meaning (2). Furthermore, when a user removes the pin, the application deletes the pinned task.
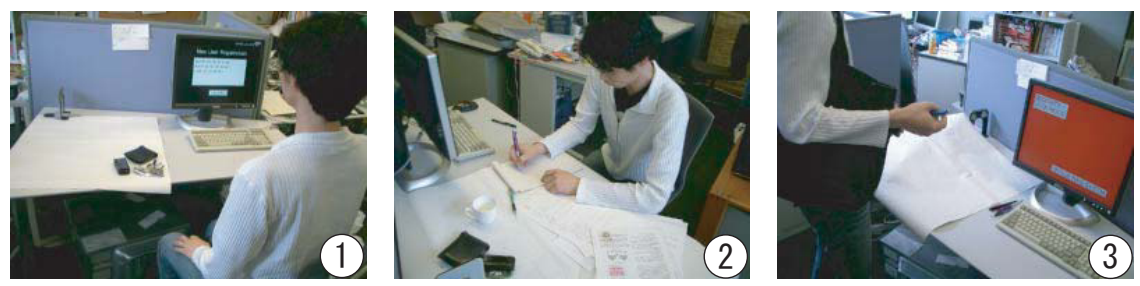

Fig. 9. Managing objects Covered with Smart-Furoshiki 

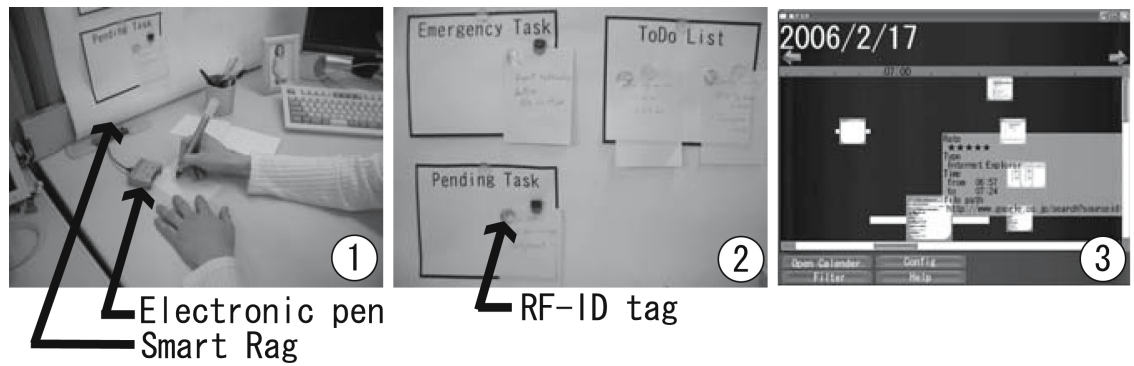

Fig. 10. 1:Writing memo pad 2:Pinned tasks 3:Timeline viwer

The pinned tasks are shared in the group, and also the user can check the tasks wherever the user can connect the network. Finally, these task histories are referenced on a PC by Timeline viewer (3). Users can see the task histories, and retrieve before tasks easily.

\section{Related Work}

There is a research that aims to realize a smart carpet that identifies things on it [2]. However the size is too large to be used as a tablecloth or a tapestry like Smart-Furoshiki. bYOB developed at MIT media Lab is a smart bag with embedded sensors [5]. bYOB is built in antenna of RF reader. Our Smart-Furoshiki is made from a conductive textile and can work as the antenna itself. Therefore Smart-Furoshiki is thinner and cheaper than that of bYOB. Other research [1] [9] are also using sensorized fabrics. The aim of these research is to obtain biometrics information at wearable environment. Our research target, on the other hand, is for collaborative work at office environment.. Electronic Tablecloth made from E-broidery [8] is an electronic conductive textile can read an RF-ID tag. However the usage of it is limited to tablecloth. Smart-Furoshiki has more flexibility.

\section{Conclusion}

We have developed a cloth-like RFID system called "Smart-Furoshiki" that allows users to manage phisical objects in inexpensive and environment-aware way. We also provide a software framework for management RFID information and application control called Smart-furoshiki Middleware. Smart-Furoshiki Middleware can recognize the changing its own shape autonomously through combination of detecting RFID tags and antennas. Moreover, Smart-Furoshiki's flexibility allows to turn fold this into any shape. Using these features, Smart-Furoshiki can be based on a lots of applications. To show the utilization of Smart-Furoshiki for the various purposes at office environment, we implemented demonstrations based on three scenarios. First one is the collaboration between mobile PCs on the laying Smart-Furoshiki At the second demo by using SmartFuroshiki for covering objects, users can keep privacy in easy way. As the third application Smart-Furoshiki, hanged on a wall, helps tasks management between cyber and physical memo papers. Secondly, to accumulate context information even when 
users outside environment, we provide mobile-seize Smart-Furoshiki. We proved two type of Furoshiki. Large size Smart-Furoshiki can detect objects ID and place using 8 RFID antennas which are made from flexible fabric. Mobile-size has 4 RFID antennas, chargeable battery, tiny RFID readers, and Bluetooth communication module. By using two type of Smart-Furoshiki, ubiquitous applications can accumulate users' context easily and contentiously.

\section{Acknowledgement}

This research has been conducted as part of Ubila Project supported by Ministry of Internal Affairs and Communications, Japan.

\section{References}

1. De Rossi, D., Santa, A., Mazzoldi, A.: Dressware: wearable piezo- and thermoresistive fabrics forergonomics and rehabilitation. In: Engineering in Medicine and Biology society, 1997. Proceedings of the 19th Annual International Conference of the IEEE, 5th edn, pp. 1880-1883 (1997)

2. Fukumoto, M., Shinagawa, M.: Carpetlan: A novel indoor wireless(-like) networking and positioning system. In: Beigl, M., Intille, S.S., Rekimoto, J., Tokuda, H. (eds.) UbiComp 2005. LNCS, vol. 3660, pp. 1-18. Springer, Heidelberg (2005)

3. Kohtake, N., Ohsawa, R., Yonezawa, T., Matsukura, Y., Iwai, M., Takashio, K., Tokuda, H.: u-Texture:Self-organizable Universal Panels for Creating Smart Surroundings. In: Beigl, M., Intille, S.S., Rekimoto, J., Tokuda, H. (eds.) UbiComp 2005. LNCS, vol. 3660, pp. 19-36. Springer, Heidelberg (2005)

4. Kohtake, N., Yonezawa, T., Ohsawa, R., Matsukura, Y., Takashio, K., Tokuda, H.: Creating pervasive services with self-organizable universal boards. In: Gellersen, H.-W., Want, R., Schmidt, A. (eds.) PERVASIVE 2005. LNCS, vol. 3468, pp. 187-192. Springer, Heidelberg (2005)

5. Nanda, G., Michael Bove, J.V., Cable, A.: byob (build your own bag):a computationallyenhanced modular textile system. In: Davies, N., Mynatt, E.D., Siio, I. (eds.) UbiComp 2004. LNCS, vol. 3205, Springer, Heidelberg (2004)

6. Muller-Tomfelde, C., Streitz, N., Tandler, P., Konomi, S.: Roomware: Towards the next generation of human-computer interaction based on an integrated design of real and virtual worlds. In: Carroll, J. (ed.) Human-Computer Interaction in the New Millenium, pp. 553578. Addison-Wesley, Reading

7. Pentel. Pentel airpen, http://www . airpen.jp/

8. Post, E.R., Orth, M., Russo, P.R., Gershenfeld, N.: E-broidery: design and fabrication of textile-based computing. IBM Syst. J. 39(3-4), 840-860 (2000)

9. Sensatex, I.: Smart textile, http: //www. sensatex.com/

10. Intille, S.S., Larson, K., Tapia, E.M., Beaudin, J.S., Kaushik, P., Nawyn, J., Rockinson, R.

11. Tanaka, M., Jang, J.-H.: Wearable microstrip antenna for satellite communications. In: IEICE Transaction on Communications (August 2004)

12. Yanagihara, T., Sakakibara, H., Ohsawa, R., Ideuchi, M., Kohtake, N., Iwai, M., Takashio, K., Tokuda, H.: A self configurable topology-aware network for smart materials. In: IWSAWC 2005 (June 2005) 